\title{
COVID-19 Patients with Cardiovascular Diseases: Important Laboratory Markers to Predict Prognosis
}

\author{
Amr Elkammash1", Nourhan Degheidy², Saleh Kanaan1, \\ Fairouz Farag1, Mian Ahmed', Ahmed Khalifa ${ }^{3}$ \\ ${ }^{1}$ Royal Bournemouth and Christchurch Hospitals NHS Foundation Trust, Bournemouth, UK \\ ${ }^{2}$ Medical Research Institute, Alexandria University, Alexandria, Egypt \\ ${ }^{3}$ Poole General Hospital, Poole, UK \\ Email: ^amr.elkammash@nhs.net
}

How to cite this paper: Elkammash, A., Degheidy, N., Kanaan, S., Farag, F., Ahmed, M. and Khalifa, A. (2020) COVID-19 Patients with Cardiovascular Diseases: Important Laboratory Markers to Predict Prognosis. Open Access Library Journal, 7: e6652. https://doi.org/10.4236/oalib.1106652

Received: July 24, 2020

Accepted: August 21, 2020

Published: August 24, 2020

Copyright $\odot 2020$ by author(s) and Open Access Library Inc.

This work is licensed under the Creative Commons Attribution International License (CC BY 4.0).

http://creativecommons.org/licenses/by/4.0/

(c) (i) Open Access

\begin{abstract}
Background: Patients with cardiovascular diseases are susceptible to poor outcomes in COVID-19 infection. Knowing their prognosis will help to allocate resources to provide them with the best care. This article reviews the best available literature about laboratory markers that can be done on admission of COVID-19 patients with cardiovascular problems and help to predict their prognosis. Design and Methods: Search engines such as Google Scholar, Pubmed and Google were used to collect data on published studies using combination of search words "COVID-19" and one or more of the following: mortality, Leucopenia, thrombocytopenia, Ferritin, CRP, troponin, IL-6, LDH and coagulopathy. Results: There is robust evidence that laboratory markers can predict the prognosis in COVID-19 infected patients, including those with cardiovascular problems. Poor outcomes were correlated with the following: Lymphopenia, thrombocytopenia and high LDH, hs-cTn, D-dimer, PT, FDP, Ferritin, CRP, PCT and IL-6. Elevated PCT is related to secondary bacterial infection in severe cases. IL-6 inhibitor (Tocilizumab) can be a good treatment option for severe and critical COVID-19 cases and should be further studied by randomized control trials. Conclusion: Certain laboratory markers should be requested on admission of COVID-19 patients with cardiovascular problems to improve their management and outcomes.
\end{abstract}

\section{Subject Areas}

Infectious Diseases

\section{Keywords}

COVID-19, Laboratory, Cardiovascular, Lymphopenia, Thrombocytopenia, 
CRP, Ferritin, Troponin, Fibrin Degradation Products, Procalcitonin, Interleukin-6

\section{Introduction}

COVID-19 infection (also known as SARS Co-V2) is a pandemic affecting millions of people all over the world [1]. Patients with cardiovascular problems (including hypertension, heart failure and coronary artery diseases) are considered a high risk group in the era of COVID-19 pandemic. They have worse in-hospital course and higher mortality [2]. Therefore, they are expected to need a higher level of medical care and more complex maneuvers in their management. It is important to find simple non-invasive markers that can be used at time of patient admission to predict their in-hospital course and the required equipment for their care.

This article reviews the evidence published between October 2019 and April 2020 on several laboratory markers that can predict the severity and outcome of COVID-19 infected patients. Search engines such as Google Scholar, Pubmed and Google were used to collect data on published studies using combination the search word "COVID-19" and one or more of the following: mortality, Leucopenia, thrombocytopenia, Ferritin, CRP, troponin, IL-6, LDH and coagulopathy. Only papers published in English were included. Because COVID-19 infection is a relatively new health problem and a wider view of its characteristics is required, we included all the studies published over the fore mentioned time period, with priority given to meta-analyses and systematic reviews. Studies whose results were reproduced in another larger studies or meta-analyses were excluded. Data on laboratory markers that have a significant correlation with COVID-19 outcome (based on p value) is extracted. These laboratory markers include: Lymphocytic count, hs-cTn, LDH, inflammatory markers (CRP, Ferritin, PCT and IL-6) and markers of coagulopathy (Platelets count, PT, D-dimer and FDP).

\section{Lymphocytic Count}

Low lymphocytic count (Lymphopenia) is very common in COVID-19 patients [3]. Several mechanisms were proposed for such lymphopenia [4]. Lymphocytes express ACE-2 receptors which are considered as ports for COVID-19 virus cell entry; therefore, they can be directly targeted by the virus causing cell death [5]. Lymphatic organs might also be directly damaged by the virus, but this theory needs confirmation by postmortem examination in the future. Inflammatory cytokines (such as: IL- 6 and TNF- $\alpha$ ) which are produced during infection cause lymphocyte apoptosis [6]. Another possible mechanism is that metabolic by-products that are high in severely ill COVID-19 patients may inhibit proliferation of lymphocytes [7].

Several studies have demonstrated that lower lymphocytic count is asso- 
ciated with worse prognosis and higher mortality in COVID-19 patients [2] [4]. Zhou F. et al. found that lymphocytic count was significantly lower among non-survivors compared to survivors of the infection (median value $=0.6$ vs. 1.1 $\times 10^{9} / \mathrm{L}$ respectively, $\left.\mathrm{p}<0.0001\right)$ [2]. Tan L. et al. succeeded to validate a model (Time-LYM\% model (TLM)) to predict the in-hospital course and mortality in this cohort. [4] In this study, they found that lymphocyte \% value of less than 5\% is associated with poor prognosis and high mortality.

\section{High Sensitivity Cardiac Troponin (hs-cTn)}

Several studies have illustrated that elevated level of hs-cTn is a marker of severe COVID-19 and poor prognosis. Zhou F et al. proved that median serum troponin was significantly higher among non-survivors compared to survivors of COVID-19 infection (22.2 vs. $3 \mathrm{pg} / \mathrm{ml}$ respectively, $\mathrm{p}<0.0001$ ) [2]. Such finding was further confirmed in the meta-analysis done by Lippi G et al. [8].

The mechanism of troponin rise is not fully understood. It may be due to direct damage of myocardial cells, which carry ACE 2 receptors on their surface, by the virus. Another possible cause is occurrence of acute myocardial infarction (MI); either type $1 \mathrm{MI}$ induced by plaque rupture secondary to infection or type $2 \mathrm{MI}$ due to $\mathrm{O}_{2}$ supply-demand mismatch. Nevertheless, the rise and fall of hs-cTn without ischemic symptoms and ECG changes cannot justify the diagnosis of acute MI [9].

\section{Lactate Dehydrogenase (LDH)}

High LDH carries unfavorable outcome in COVID-19 patients. Not only is it a marker of tissue damage, but also it increases lactate production. High lactate leads to activation of immune-suppressive cells, including macrophages and dendritic cells, and inhibition of cytolytic cells, such as natural killer cells and cytotoxic T-lymphocytes [10]. In the study by Zhou F. et al., LDH was significantly higher in patients who died of COVID-19 (with a median value of $521 \mathrm{vs.}$ 253.5 U/L in survivors, $\mathrm{p}<0.0001$ ) [2]. A second study by Zhou B. et al. comparing patients with very severe and severe COVID-19 infection (very severe COVID-19 was defined as having either one of the following criteria: 1) Respiratory failure in need of mechanical ventilation; 2) Shock; 3) Other organ dysfunction and Severe COVID-19 was defined as having either one of the following criteria: 1) Respiratory distress with respiratory rate more than 30 times/min; 2) Oxygen saturation $\leq 93 \%$ in resting state; 3) $\mathrm{PaO}_{2} / \mathrm{FiO}_{2} \leq 300$ $\mathrm{mmHg}$ ) revealed that $\mathrm{LDH}$ level was even higher in the very severe COVID-19 infection cohort (median value 411 vs. $195 \mathrm{U} / \mathrm{L}$ respectively, $\mathrm{p}<0.001$ ) [11]. Han Y. et al. have discovered that LDH level has a negative correlation with number of lymphocytes and their subsets, including CD3+, CD4+ and CD8+ T cells $(\mathrm{P}<$ $0.001, \mathrm{R}=-0.766,-0.771$ and -0.588 respectively) [10].

\section{Inflammatory Markers}

The levels of certain inflammatory markers are positively correlated with the se- 
verity of COVID-19 infection. These include Ferritin, CRP, PCT and IL-6. In the study by Zhou B. et al., the levels of ferritin (1006.16 vs. $291.13 \mathrm{ng} / \mathrm{ml}, \mathrm{p}<0.05$ ), CRP $(57.98 \mathrm{mg} / \mathrm{L}$ vs. $1.48 \mathrm{mg} / \mathrm{L}, \mathrm{p}<0.05)$ and PCT $(0.21 \mathrm{ng} / \mathrm{ml}$ vs. $0.05 \mathrm{ng} / \mathrm{ml}, \mathrm{P}$ $<0.05)$ were significantly higher in patients with very severe COVID-19 infection compared with those with severe disease. They explained that by the presence of secondary bacterial infection in the patients with very severe infection; the protection from which should be a vital goal to reduce mortality in this group. [11]. This fact was further confirmed by a meta-analysis by Lippi G et al. [12]. Wang L. et al. found a strong positive correlation between the level of CRP and the diameter of lung lesions and severity of presentation in COVID-19 patients $(\mathrm{R}=0.873$ and 0.734 respectively, $\mathrm{P}<0.001)$ [13].

IL-6 level has the strongest clinical evidence among other inflammatory markers regarding its association with COVID-19 infection severity. A meta-analysis of 16 studies by Coomes E. et al., including 1302 patients, concluded that higher IL-6 level was a strong predictor of complicated COVID-19 infection; probably due to excessive host immune response and autoimmune injury [14]. Higher IL-6 level was accompanied with higher incidence of respiratory failure and a need for mechanical ventilation in the study by Herold $\mathrm{T}$ et al., especially if the level of IL-6 exceeded $80 \mathrm{pg} / \mathrm{ml}$ [15]. Based on the about evidence, IL-6 inhibitor (Tocilizumab) was tried on 21 patients with severe and critical COVID-19 infection in China and showed a high cure rate and no complications [16]. However, the results of this trial need further validation by larger scale randomized trials in the future.

\section{Markers of Coagulopathy}

Coagulopathy is highly prevalent among COVID-19 patients. It is clinically manifested in the form of disseminated intravascular coagulation (DIC), arterial and venous thrombosis. This can be explained by excessive inflammation, hypoxia and lack of mobilization in those patients [17]. Laboratory markers of coagulopathy includes: thrombocytopenia and high PT, D-dimer and FDP levels [18]. These markers can predict more severe infection and worse outcomes. In the study by Tang $\mathrm{N}$ et al., patients who died of COVID-19 infection had significantly prolonged PT (median value 15.5 vs. 13.6 secs, $\mathrm{p}<0.001$ ), higher levels of FDP (median value 7.6 vs. $4 \mathrm{ug} / \mathrm{ml}, \mathrm{p}<0.001$ ) and $\mathrm{D}$-dimer (median value 2.12 vs. $0.61 \mathrm{ug} / \mathrm{ml}, \mathrm{p}<0.001)$ compared to survivors [19]. Similarly, the level of D-dimer was significantly higher (median value $5.2 \mathrm{vs} 0.6 \mathrm{ug} / \mathrm{ml}, \mathrm{p}<0.0001$ ) and platelets count was significantly lower (median value 165.5 vs. $220 \times 10^{9} / \mathrm{L}, \mathrm{p}<0.0001$ ) among non-survivors of COVID-19 infection in the study by Zhou F. et al. [2].

A meta-analysis by Lippi G. et al. showed significantly lower platelets count among patients with severe COVID-19 infection (mean difference $-31 \times 10^{9} / \mathrm{L}$, 95\% CI: -35 to $-29 \times 10^{9} / \mathrm{L}$ ) and those who died of the infection (mean difference $-48 \times 10^{9} / \mathrm{L} ; 95 \% \mathrm{CI},-57$ to $\left.-39 \times 10^{9} / \mathrm{L}\right)$. Thrombocytopenia was also associated with five-fold higher odds of having severe disease (OR: 5.13; 95\% CI: 
$1.81-14.58)[20]$.

\section{Conclusion}

There are several recently published studies on the predictive value of particular laboratory markers for the outcome of COVID-19 infection. Cardiac patients deserve to get such markers at time of admission because they are a high-risk group. The adoption of this practice can help to improve the management and modify the outcome in such patients. It is worth doing dedicated research on this group in the future.

\section{Acknowledgements}

Great thanks to Prof. Dr. Mohamed Ayman Abdel Hay, Professor of Cardiology, Alexandria University for his support in the proofreading of this paper.

\section{Conflicts of Interest}

The authors declare no conflicts of interest regarding the publication of this paper.

\section{References}

[1] WHO. Coronavirus Disease (COVID-2019) Situation Reports. https://www.who.int/emergencies/diseases/novel-coronavirus-2019/situation-reports

[2] Zhou, F., Yu, T., Du, R., et al. (2020) Clinical Course and Risk Factors for Mortality of Adult Inpatients with COVID-19 in Wuhan, China: A Retrospective Cohort Study. The Lancet, 395, 1054-1062. https://doi.org/10.1016/S0140-6736(20)30566-3

[3] Wang, Y., Wang, Y., Chen, Y. and Qin, Q.S. (2020) Unique Epidemiological and Clinical Features of the Emerging 2019 Novel Coronavirus Pneumonia (COVID-19) Implicate Special Control Measures. Journal of Medical Virology, 92, 568-576. https://doi.org/10.1002/jmv.25748

[4] Tan, L., Wang, Q., Zhang, D.Y., Ding, J.Y., Huang, Q.C., Tang, Y.Q., Wang, Q.S. and Miao, H.M. (2020) Lymphopenia Predicts Disease Severity of COVID-19: A Descriptive and Predictive Study. Signal Transduction and Targeted Therapy, 5, 16-18. https://doi.org/10.1038/s41392-020-0159-1

[5] Xu, H., Zhong, L., Deng, J., et al. (2020) High Expression of ACE2 Receptor of 2019-nCoV on the Epithelial Cells of Oral Mucosa. International Journal of Oral Science, 12, Article No. 8. https://doi.org/10.1038/s41368-020-0074-x

[6] Liao, Y.-C., Liang, W.-G., Chen, F.-W., Hsu, J.-H., Yang, J.J. and Chang, M.S. (2002) IL-19 Induces Production of IL-6 and TNF- $\alpha$ and Results in Cell Apoptosis through TNF- $\alpha$. The Journal of Immunology, 169, 4288-4297.

https://doi.org/10.4049/jimmunol.169.8.4288

[7] Fischer, K., Hoffmann, P., Voelkl, S., et al. (2007) Inhibitory Effect of Tumor Cell-Derived Lactic Acid on Human T Cells. Blood, 109, 3812-3819. https://doi.org/10.1182/blood-2006-07-035972

[8] Lippi, G., Lavie, C.J. and Sanchis-Gomar, F. (2020) Cardiac Troponin I in Patients with Coronavirus Disease 2019 (COVID-19): Evidence from a Meta-Analysis. Progress in Cardiovascular Diseases, 63, 390-391. https://doi.org/10.1016/j.pcad.2020.03.001 
[9] Januzzi Jr., J.L. (2020) Troponin and BNP Use in COVID-19. American College of Cardiology.

https://www.acc.org/latest-in-cardiology/articles/2020/03/18/15/25/troponin-and-b $\underline{\text { np-use-in-covid19 }}$

[10] Han, Y., Zhang, H., Mu, S., et al. (2020) Lactate Dehydrogenase, a Risk Factor of Severe COVID-19 Patients. MedRxiv. https://doi.org/10.1101/2020.03.24.20040162

[11] Zhou, B., She, J.Q., Wang, Y.D. and Ma, X.C. (2019) Utility of Ferritin, Procalcitonin, and C-Reactive Protein in Severe Patients with 2019 Novel Coronavirus Disease. Current Status: Posted, 1-13. https://doi.org/10.21203/rs.3.rs-18079/v1

[12] Lippi, G. and Plebani, M. (2020) Procalcitonin in Patients with Severe Coronavirus Disease 2019 (COVID-19): A Meta-Analysis. Clinica Chimica Acta, 505, 190-191. https://doi.org/10.1016/i.cca.2020.03.004

[13] Ling, W. (2020) C-Reactive Protein Levels in the Early Stage of COVID-19. Médecine et Maladies Infectieuses, 50, 7-9.

[14] Coomes, E.A. and Haghbayan, H. (2020) Interleukin-6 in COVID-19: A Systematic Review and Meta-Analysis. MedRxiv. https://doi.org/10.1101/2020.03.30.20048058

[15] Herold, T., Jurinovic, V., Arnreich, C., et al. (2020) Level of IL-6 Predicts Respiratory Failure in Hospitalized Symptomatic COVID-19 Patients. MedRxiv. https://doi.org/10.1101/2020.04.01.20047381

[16] Xu, X., Han, M., Li, T., et al. (2020) Effective Treatment of Severe COVID-19 Patients with Tocilizumab. ChinaXiv, 1-12.

[17] Klok, F.A., Kruip, M.J.H.A., Van Der Meer, N.J.M., et al. (2020) Incidence of Thrombotic Complications in Critically Ill ICU Patients with COVID-19. Thrombosis Research, 191, 145-147. https://doi.org/10.1016/j.thromres.2020.04.013

[18] Giannis, D., Ziogas, I.A. and Gianni, P. (2020) Coagulation Disorders in Coronavirus Infected Patients: COVID-19, SARS-CoV-1, MERS-CoV and Lessons from the Past. Journal of Clinical Virology, 127, Article ID: 104362. https://doi.org/10.1016/j.jcv.2020.104362

[19] Tang, N., Li, D., Wang, X., et al. (2020) Abnormal Coagulation Parameters Are Associated with Poor Prognosis in Patients with Novel Coronavirus Pneumonia. Journal of Thrombosis and Haemostasis, 18, 844-847. https://doi.org/10.1111/jth.14768

[20] Lippi, G., Plebani, M. and Henry, B.M. (2020) Thrombocytopenia Is Associated with Severe Coronavirus Disease 2019 (COVID-19) Infections: A Meta-Analysis. Clinica Chimica Acta, 506, 145-148. https://doi.org/10.1016/j.cca.2020.03.022 


\section{Abbreviations}

hs-cTn: high sensitivity cardiac troponin,

PT: Prothrombin time,

FDP: fibrin degradation product,

PCT: Procalcitonin,

IL-6: Interleukin-6,

LDH: lactate dehydrogenase,

CRP: C-reactive protein,

DIC: disseminated intravascular coagulation,

TNF: Tumor Necrosis Factor. 